Nursing Theory in the Quest for the Sustainable Development Goals

William E. Rosa, Barbara M. Dossey, Mary Koithan, Mary Jo Kreitzer, Phalakshi Manjrekar, Afaf I. Meleis, Donatilla Mukamana, Marilyn A. Ray, \& Jean Watson

William E. Rosa, RN; MS; FAAN, RWJF Future of Nursing Scholar, University of Pennsylvania School of Nursing, 418 Curie Blvd., Philadelphia, PA, 19104. wrosa@nursing.upenn.edu

Barbara M. Dossey, RN; PhD; FAAN, Co-Director, International Nurse Coach Association, North Miami, FL, International Co-Director, Nightingale Initiative for Global Health, Santa Fe, NM. barbara@dosseydossey.com

Mary Koithan, RN; PhD; FAAN, Anne Furrow Professor and Associate Dean, University of Arizona College of Nursing, Tucson, AZ. mkoithan@email.arizona.edu

Mary Jo Kreitzer, RN; PhD; FAAN, Director, Earl E. Bakken Center for Spirituality \& Healing, Professor, School of Nursing, University of Minnesota, Minneapolis, MN. kreit003@umn.edu

Phalakshi Manjrekar, RN; PhD, Director of Nursing, P.D. Hinduja National Hospital, Mumbai, India. phalakshi.manjrekar@hindujahospital.com

Afaf I. Meleis, RN; PhD; FAAN, Dean Emerita and Professor of Nursing and Sociology, University of Pennsylvania School of Nursing, Philadelphia, PA. meleis@nursing.upenn.edu Donatilla Mukamana, RN; PhD, Dean, University of Rwanda School of Nursing \& Midwifery, Kigali, Rwanda, East Africa.donatillamu1@gmail.com

Marilyn A. Ray, RN; PhD; FAAN, Colonel (Ret.), Unites States Air Force, Nurse Corps, Partnership Liaison, Caring-Based Academic Partnership in Excellence: Veteran RNs in Primary 
Care (CAPE-V) Grant, Emeritus Professor, Florida Atlantic University Christine E. Lynn

College of Nursing, Boca Raton, FL.mray@fau.edu

Jean Watson, RN; PhD; FAAN, Founder \& Director, Watson Caring Science Institute,

Boulder, CO.jean@watsoncaringscience.org

Corresponding author: William E. Rosa,wrosa@nursing.upenn.edu, 646.689.4044

Keywords: Sustainable Development Goals; SDGs; United Nations; global health 
Nursing Theory in the Quest for the Sustainable Development Goals 


\section{NURSING THEORY}

Nursing Theory in the Quest for the Sustainable Development Goals

Some may question the role of nursing theory and related paradigms in the age of sustainable development. True, what is needed now is action - measurable change with a focus on outcomes showing improved health and wellbeing and a demonstrable commitment to equity, inclusion, universal respect, and environmental thriving. The profession needs leaders to advance nursing's political voice and harness mutually beneficial, long-term partnerships with stakeholders in the economic, financial, agricultural, energy, and business sectors. One tangible goal, being promoted through campaigns such as Nursing Now (n.d.), is having a nursing presence at all decision-making tables related to health policy that address the myriad determinants of health. With 2020 claimed as the Year of the Nurse and Midwife (World Health Organization [WHO], 2019), we must not only honor our skills to adapt, collaborate, and progress, but also celebrate our historical roots that establish nurses as sojourners with society and lightkeepers in a chronically dehumanizing healthcare system.

Why is talk of caring, integrality, and a humanistic nursing lens essential in the context of the 17 United Nations (UN) Sustainable Development Goals (SDGs) (UN, 2016)? Because theory-guided practice continues to inform discipline-specific care as well as agendas of advocacy. Nurses across settings and in all nations worldwide play pivotal roles in the global attainment of the SDGs through acts of concerned citizenship and professional leadership (Rosa, 2017; Rosa et al., 2019). Theory breathes into the world the determination of Florence Nightingale, the grit of Lillian Wald, and the soul of all global nurse leaders who have gone unnamed or uncelebrated. Theory is both a background on which to build and a foreground upon which to envision (Meleis, 2018). You may ask, have we not worn out the scholarly dialogue related to theory and theoretical implications of nursing care? And yet theory continues to 
NURSING THEORY

demonstrate direct links to the world's current global agendas and the needs of our planet at large.

Never before has a practice rooted in our professional heritage been so vital. While we must be able to adopt interdisciplinary solutions to modern day problems, we must also be able to give language to our unique contributions in ways that honor nursing's heritage and celebrate our shared humanity with those we serve. In fact, the authors contend that nursing theory is called to evolve and invite a next generation of visionaries to meet the future needs of the global village, ensuring planetary survival and thriving. There are several important points to consider as we strive to keep one foot upon a future of potential SDG attainment and the other firmly balanced on our theoretical-disciplinary foundations. Importantly, all extant nursing theories inform the profession's role in the global agenda through knowledge development and the promotion of theory-guided practice. However, only a select few are discussed herein to make explicit the direct links between nursing science and the SDGs, specifically, caring science, transcultural nursing theory, and integral and integrative nursing.

First, caring is a critical way of being, doing, and knowing in the world while attending to each of the 17 SDGs. The caring sciences inform 'how' we practice and contribute to a global society where every human life matters, guided by an ethic of 'Belonging' to universal cosmic love (Watson, 2018). This premise of nursing - the very essence of our profession - strives to protect and engender dignity as a primary tenet and at all costs. For 40 years, Watson's theory has reminded nurses worldwide that the power of a caring moment is transpersonal, transcending time, space, and physicality, and that a heart-centered approach to practice is what humanity needs in these times of extreme vulnerability (Rosa et al., 2019; Watson, 2012). The SDGs call for a civil society where all lives matter by abolishing the plights of poverty and hunger. Caring 
NURSING THEORY

gives us a currency of shared humanity with which to empower and nourish not just economic livelihoods, but people as human beings who bear highly individualized stories and narratives. Caring gives us both an artistic texture and scientific premise with which to make new connections between caring, peace, and social/moral justice.

Second, the many cultures among nations and communities deserve our attention while striving to achieve the SDGs. Leininger saw a world where culture care was prioritized as nurses sought to maintain and improve the health of all people (Leininger, 1970; McFarland \& WehbeAlamah, 2018). Self-reflection, self-awareness, openness to diversity, and a genuine willingness to see different perspectives is necessary to engage with cultural humility (Foronda, Baptiste, Reinholdt, \& Ousman, 2016). Equity does not exist without cultural humility. Ray (2016) has emphasized the need to remember the following when working in transcultural nursing arenas: the essence of caring (compassion/love as the guiding force); transcultural caring ethics (a moral caring experience promoting ethical engagement); transcultural context (varied personalcommunal-societal lived experiences); and universal sources (spiritual/religious traditions that inform the transcultural caring relationship). Ray's (2016) theory provides a cultural roadmap to navigate the complexities of realizing the SDGs across varied nations, religions, countries and governments with different priorities and laws, and an endless number of subcultures within cultural communities with distinct values and identities.

Third, the SDGs - quite literally - reflect integral nursing theory and an integrative lens. Dossey (2016) reminds nurses that healing is always at the center of nursing care, even in the absence of cure. We can always promote greater wholeness and soundness in any given setting through our authentic presence, deep listening, holistic skill set, and clear intentionality. This is particularly relevant in resource-poor settings where certain technologies and interventions 
NURSING THEORY

remain a pipedream. Integral theory (Dossey, 2016) asks nurses to continually view the SDGs, health and wellbeing through four quadrants of experience: individual interior

(psychological/spiritual), individual exterior (physiological/behavioral), collective interior (relational/cultural), and collective exterior (structural/social). If the SDGs are to be achieved by 2030, we must take the deep dive into these quadrants of life and living on a consistent basis.

Furthermore, integrative nursing forerunners Kreitzer and Koithan (2019) insist we take a whole-person and whole-system stance, intervening in a manner that respects inherent healing properties and empowering the recipient of care while creating a system that is sustainable and humane (see Table 1). This is a crucial component of social justice and activism that equips nurses to think broader and substantiate practice grounded in knowledge of dynamic, complex, ever-changing system-level factors. The principles of integrative nursing, consistent and aligned with all of the above nursing theories, provide practical and unambiguous guidance that shapes and directs nursing action towards achievement of the SDGs. Integrative nursing allows us to ride the wave between the needs of the individual and the collective, trusting in the power of nature to restore and enliven.

The theories discussed above - among others - have been employed in practice settings globally. Examples include the conceptual development of caring science literacies and translation to research in South Africa, Peru, Jordan, and Israel (Lee, Palmieri, \& Watson, 2017). Leininger's theory has been used as a premise of nursing care and research for indigenous populations in countries like the United States and Kenya and immigrants confronting crosscultural challenges (McFarland \& Wehbe-Alamah, 2018). Transcultural caring has been applied to healthcare settings in countries such as Thailand, Norway, Ecuador, China, the Philippines, and Haiti, emphasizing culturally relevant nursing across milieus (Ray, 2016). The theory of 
NURSING THEORY

integral nursing has been the basis for international health partnerships in India (Dossey, Beck, Oerther, \& Manjrekar, 2017) and serves as the ethos of organizations like the Nightingale Initiative for Global Health (2019), which has representation in Uganda, as well as consultative status at the UN. Integrative nursing has been contextualized into educational, practice, and research domains in many nations, including Germany, Turkey, Iceland, and Sweden, challenging the status quo of healthcare by demonstrating whole-person and whole-people care at a systems level (Kreitzer \& Koithan, 2019).

Next to consider is that if the SDGs are to be realized, we must honor the importance of middle-range and situation-specific theories for use in dynamic and diverse environments. For instance, Mukamana's genocide rape trauma management work is based on her grounded theory research and addresses the biopsychosocial needs of Rwandan genocide survivors, supporting the advancement of social services to promote health equity (SDG 3), gender equality (SDG 5), and economic opportunity for all (SDG 8) within Rwanda (Mukamana, Collins, \& Rosa, 2018; Mukamana, Brysiewicz, Collins, \& Rosa, 2018). Another example is Meleis’ $(2010,2019)$ transitions theory, which has been applied for a host of populations confronting various chronic illnesses and may prove reliable to help guide nursing service in the face of evolving global transitions, such as the climate crisis (SDG 13) and the multidimensional health impacts due to a significant loss of biodiversity (SDGs 14 and 15). In fact, transitions are what the SDGs are all about: accountable and peaceful transnational transitions toward respect, inclusion, thriving, wellbeing, and health in an ever-changing world.

Finally, theory is not static. Theory rises to meet the changing tides of the day. Rosa (2017a) has called for continued theory evolution to inform needs at a planetary level. If nurses are to mitigate the degradation of the biosphere and promote planetary health at institutional, 


\section{NURSING THEORY}

national, and global levels, we must have theories that supply nurses with a structure for disciplinary thinking and service in these domains. We must move toward planetary caring and infuse practice, education, research, and policy with the concept of One Mind-One Health-One Planet (Rosa, 2017b, 2019). The notion of planetary citizenship has been previously discussed (Rosa, 2017b) and carries with it the idea that human health and wellbeing is a farce without planetary interconnectedness and consciousness linking humanity and human survival to animal species, ecosystems, and all aspects of the environment. Planetary citizenship is built on concepts of caring, integrality and integrative systems thinking, transcultural inclusion, and the courage needed to attend to the planet's transitions with disciplinary integrity. We must consider ourselves planetary citizens living in a global world; facilitators of caring-healing across cultures and contexts tending to people and the environment through integral-integrative models that produce the measures the empiricists demand. Theory must grow as we do at individual and group levels, as both citizens and professionals, today and in the future.

Meleis (2017) wrote that nurses "must systematically and deliberately plan their work, action, practice, and research toward supporting and/or advocating for the SDGs" (p. 526). However, nurses' contributions to the SDGs will always be lacking if we overlook the role of theory to inform how we think and position ourselves in the world. Theory is language, expression, power, creativity, resilience, heritage, tradition. It is also a key guiding aspect of our professional future. The SDGs rest on five main areas: People, Planet, Peace, Prosperity, and Partnerships. Nursing theory has the potential to get us there - to experience a kinder and healthier world built on the scholarship and science of those that came before and invite a forum of action for those that are yet to come. Nursing theory is the lineage that connects us across time - now and beyond 2030. 


\section{References}

Dossey, B.M. (2016). Nursing: holistic, integral, and integrative - local to global. In B.M.

Dossey \& L. Keegan (Eds.), Holistic nursing: A handbook for practice ( $7^{\text {th }}$ ed., pp. 3-52). Burlington, MA: Jones \& Bartlett.

Dossey, B.M., Beck, D.M., Oerther, S., \& Manjrekar, P. (2017). Florence Nightingale's legacy: The rationale for an integral worldview in achieving the Sustainable Development Goals. In W. Rosa (Ed.), A new era in global health: Nursing and the United Nations 2030 Agenda for Sustainable Development (pp. 149-178). New York, NY: Springer Publishing.

Foronda, C., Baptiste, D.L., Reinholdt, M.M., \& Ousman, K. (2016). Cultural humility: A concept analysis. Journal of Transcultural Nursing, 27(3), 210-217.

Kreitzer, M.J., \& Koithan, M. (2019). Integrative nursing (2 ${ }^{\text {nd }}$ ed.). New York, NY: Oxford University Press.

Lee, S.M., Palmieri, P.A., \& Watson, J. (Eds.). (2017). Global advances in human caring literacy. New York, NY: Springer Publishing.

Leininger, M. (1970). Nursing and anthropology: Two worlds to blend. New York: John Wiley \& Sons.

McFarland, M., \& Wehbe-Alamah, H.B. (Eds.) (2018). Leininger's transcultural nursing: concepts, theories, research, \& practice ( $4^{\text {th }}$ ed.). New York: McGraw-Hill Education.

Meleis, A.I. (2010). Transitions theory: Middle range and situation specific theories in nursing research and practice. New York, NY: Springer Publishing.

Meleis, A.I. (2018). Theoretical nursing: Development and progress $\left(6^{\text {th }}\right.$ ed.). Philadelphia, PA: Wolters Kluwer.

Meleis, A.I. (2019). Afaf Meleis' transitions theory. In M.C. Smith (Ed.), Nursing theories and nursing practice ( $5^{\text {th }}$ ed; pp. 353-370). Philadelphia, PA: F.A. Davis.

Mukamana, D., Brysiewicz, P., Collins, A., \& Rosa, W. (2018). Genocide rape trauma management: An integrated framework for supporting survivors. Advances in Nursing Science, 41(1), 41-56.

Mukamana, D., Collins, A., \& Rosa, W. (2018). Genocide rape trauma: A conceptual framework for understanding the psychological suffering of Rwandan survivors. Research and Theory for Nursing Practice, 32(2), 125-143. 


\section{NURSING THEORY}

Nightingale Initiative for Global Health. (2019). Home. Retrieved from https://www.nighvision.net

Nursing Now. (n.d). A global campaign to raise the profile of nursing. Retrieved from https://www.icn.ch/what-we-do/campaigns/nursing-now

Ray, M.A. (2016). Transcultural caring dynamics in nursing and health care ( $2^{\text {nd }}$ ed.). Philadelphia, PA: F.A. Davis.

Rosa, W. (2017). A new era in global health: Nursing and the United Nations 2030 Agenda for Sustainable Development. New York, NY: Springer Publishing.

Rosa, W. (2017a). A call for planetary thinking in theory and knowledge development. Research and Theory for Nursing Practice, 31(2), 93-95.

Rosa, W. (2017b). One mind, one health, one planet - a pledge to planetary citizenship. In W. Rosa (Ed.), A new era in global health: Nursing and the United Nations 2030 Agenda for Sustainable Development (pp. 517-520). New York, NY: Springer Publishing.

Rosa, W. (2019). Toward planetary caring: Sustainable health and well-being for all. In Rosa, W., Horton-Deutsch, S., \& Watson, J. (Eds.), A handbook for caring science: Expanding the paradigm (pp. 511-526). New York, NY: Springer Publishing.

Rosa, W., Horton-Deutsch, S., Watson, J., Ray, M.A., Smith, M.C., Turkel, M.C., Gullett, D.G., \& Hernandez-Kurtland, G. (Eds.). (2019). A handbook for caring science: Expanding the paradigm. New York, NY: Springer Publishing.

Rosa, W.E., Sullivan-Marx, E., Kurth, A.E., Shamian, J., Shaw, H.K., Wilson, L.L., \& Crisp, N. (2019). Nursing and midwifery advocacy to lead the United Nations Systainable Development Agenda. Nursing Outlook, 67(6), 628-641.

United Nations. (2016). Transforming our world: The 2030 Agenda for Sustainable Development. Retrieved from https://sustainabledevelopment.un.org/content/documents/ 21252030\%20 Agenda\%20for\%20Sustainable\%20Development\%20web.pdf

Watson, J. (2012). Human caring science: A theory of nursing ( $2^{\text {nd }}$ ed.). Sudbury, MA: Jones \& Bartlett.

Watson, J. (2018). Unitary caring science: Philosophy and praxis of nursing. Louisville, CO: University Press of Colorado.

World Health Organization (2019). WHO Executive board of directors declares 2020 as the year of the nurse and midwife. Retrieved from https://www.who.int/hrh/news/2019/2020year-of-nurses/en/ 
NURSING THEORY

\section{Table 1. Principles of Integrative Nursing}

1. Human beings are inseparable from their environments.

2. Human beings have the innate capacity for health and wellbeing.

3. Nature has healing and restorative properties that contribute to health and wellbeing.

4. Integrative nursing is person-centered and relationship-based.

5. Integrative nursing practice is informed by evidence and uses the full range of therapeutic modalities to support/augment the healing process, moving from least intensive/invasive to more, depending on need and context.

6. Integrative nursing focuses on the health and wellbeing of caregivers as well as those they serve.

Reprinted with permission. Kreitzer, MJ \& Koithan, M. (2019). Integrative nursing (2 ${ }^{\text {nd }}$ ed). New York, NY: Oxford University Press. 